\title{
Uma visão da mobilidade urbana: passado, presente e futuro
}

\author{
A vision of urban mobility: past, present and future \\ Una visión de la movilidad urbana: pasado, presente y futuro \\ Une vision de la mobilité urbaine: passé, présent et futur
}

\section{Gabriel Campbell de Oliveira gabrielcampbell04@gmail.com Universidade de Taubaté (Unitau)}

\section{Filipe Wiltgen iD}

Ifwbarbosa@gmail.com Universidade de Taubaté (Unitau)

\section{Resumo}

Este artigo mostra uma visão temporal da mobilidade humana no mundo, assim como seus efeitos na cultura, na sociedade, no meio ambiente e na economia. O impacto que o passado teve na evolução técnicocientífica e cultural, sob o aspecto dos veículos utilizados para deslocamentos curtos e rápidos dentro de centros urbanos, até hoje é importante para o desenvolvimento humano. A análise crítica relativa ao panorama presente deve ser capaz de identificar os principais desafios da mobilidade, quer seja para o lazer, quer seja para o trabalho diário, imaginando como os seres humanos deverão se locomover no futuro para serem sustentáveis, eficazes e estruturados de forma que seus meios de transporte possam ser parte natural e integral de uma determinada localidade. Por fim, o artigo mostra os modelos e ideias adotadas em cidades que tiveram sucesso em adaptar seus meios de transporte integrando seus anseios e princípios culturais com a mobilidade urbana.

Palavras-chave: Mobilidade urbana. Transporte. Veículos a propulsão humana.

\begin{abstract}
This paper provides a temporal analysis of human mobility in the world, as well as its effects on culture, society, environment, and economy. The impact that the past had on scientific and cultural technical evolution, from the aspect of vehicles used for short and fast commuting within urban centers to this day is important for human development. The critical analysis of the present scenario should be able to identify the main challenges of mobility, whether for leisure or daily work. Forecasting how humans should move in the future to be sustainable, effective and structured in such a way that their means of transportation can be a natural and integral part of a given locality. Finally, this paper shows models and ideas adopted in cities that have succeeded in adapting their means of transportation by integrating their aspirations and cultural principles with urban mobility.
\end{abstract}

Keywords: Urban mobility. Transport. Human powered vehicle.

\section{Resumen}

Este trabajo muestra una visión temporal de la movilidad urbana en el mundo, así como sus efectos en la cultura y sociedad, en el medio ambiente y en la economía. El impacto que el pasado tuvo en la evolución técnico-científica y cultural, bajo el aspecto de los vehículos utilizados para desplazamiento humano. El análisis crítico relativo al escenario actual debe ser capaz de identificar los principales desafíos de la movilidad, ya sea para el ocio o trabajo diario. Imaginando como los seres humanos deberán desplazarse en el futuro objetivando ser sostenibles, efectivos y estructurados de tal manera que sus medios de locomoción 
puedan ser parte natural e integral de una determinada localidad. Finalmente, el trabajo muestra los modelos e ideas adoptadas en ciudades que lograron éxito en adaptar sus medios de transporte integrando sus deseos y principios culturales a la movilidad urbana.

Palabras-clave: Movilidad urbana. Transporte. Vehículos de propulsión humana.

\begin{abstract}
Résumé
Cet article montre une vision au cours du temps de la mobilité humaine dans le monde, bien comme ses effets sur la culture et la société, l'environnement et l'économie. L'impact que le passé a eu sur l'évolution technico-scientifique et sur l'évolution culturelle, concernant des véhicules utilisés pour les déplacements courts et rapides dans les centres urbains, est, à ce jour, important pour le développement humain. L'analyse critique du scénario actuel doit permettre d'identifier les principaux défis de la mobilité, soit pour les loisirs ou soit pour le travail quotidien. On imagine comment les humains devraient se déplacer dans le futur de manière durable, efficace et structuré de façon que leurs moyens de transport puissent être une partie naturelle et intégrante d'une localité donnée. Pour finir, l'article montre les modèles et les idées adoptés dans des villes où on a pu réussir à adapter les moyens de transport en intégrant leurs aspirations et principes culturels à la mobilité urbaine.
\end{abstract}

Mots-clés: Mobilité urbaine. Transport. Véhicules à propulsion humaine.

\title{
1 Introdução
}

A mobilidade urbana é um tema que sempre esteve presente na discussão de modelo de sociedade. Com o rápido crescimento populacional experimentado nos últimos anos, associado ao desenvolvimento de novas tecnologias, o presente e o futuro do transporte se tornaram bastante dinâmicos. Os fatores humanos e sociais, em conjunto com o desenvolvimento tecnológico, são fundamentais na determinação do caminho que a locomoção de pessoas irá seguir no futuro próximo (SILVEIRA; MAIA, 2015).

Cada vez mais são observadas pesquisas científicas, empresas de tecnologia e políticas públicas associadas ao tema da mobilidade, pois é algo crucial no futuro. Hoje, a matriz energética mundial está centrada nos combustíveis fósseis, e o transporte representa uma parcela significativa desse consumo (IEA, 2018). Além disso, a questão da eficiência na locomoção das pessoas, considerando o gasto de energia, a poluição e o trânsito enfrentado nas cidades, torna essa discussão ainda mais relevante e necessária.

Este artigo aborda o passado, o presente e o futuro da mobilidade urbana considerando o contexto de problemas de nossa sociedade no trânsito e a matriz energética, associada ao desenvolvimento de novas tecnologias, além, é claro, da necessidade do ser humano em se locomover de forma sustentável e ecologicamente responsável.

Por fim, esta pesquisa discute o futuro da mobilidade urbana observando a tendência atual das pesquisas e investimentos, sempre observando em três tempos distintos: passado, presente e futuro.

A metodologia utilizada nesta pesquisa foi um estudo descritivo e exploratório, que usa a análise de dados científicos através de uma abordagem qualitativa, quantitativa e comparativa entre os tipos de veículos utilizados pelos seres humanos em três períodos distintas (passado, presente e futuro da mobilidade urbana), com foco nos veículos de tração humana, como a bicicleta e os triciclos. As análises suportam a tese de uma tendência de mudança na mobilidade urbana, apresentada neste artigo. 


\section{0 passado da mobilidade urbana}

A locomoção de pessoas é um fator importante no desenvolvimento da civilização desde os tempos mais antigos. Se mover de uma comunidade a outra significava encontrar novos produtos, formas de comércio, culturas, tecnologias e pessoas (RODRIGUE, 2017). Essas jornadas, de diferentes civilizações, foram fundamentais para a formação do mundo que existe hoje. Em um primeiro momento, a locomoção era realizada sem uso de ferramentas, ou seja, através de longas caminhadas ou mesmo nadando.

O desenvolvimento e o uso de ferramentas fizeram com que o ser humano se colocasse em vantagem no deslocamento e na mobilidade frente a outros animais. Essa evolução foi gradativa. Inicialmente, utilizando materiais simples, como pedra e madeira. Ao longo dos anos, a complexidade dessas ferramentas foi aumentando, possibilitando a criação de máquinas e dispositivos que tinham como principal objetivo otimizar os esforços dos músculos humanos para integrar e propulsionar as máquinas.

Uma dessas invenções baseadas na propulsão humana foi o barco a remo. Grandes navios romanos eram movidos através de centenas de remos (WILSON, 2004). Inicialmente, a força exercida pelas pessoas era principalmente originária de músculos, como a mãos e braços. Os grandes músculos, como os das pernas, eram utilizados somente para promover o equilíbrio ou exercer força de reação.

Ao longo do tempo, as civilizações perceberam que utilizar esses grandes músculos associados às máquinas promovia melhor eficiência nas tarefas. A partir daí, novas invenções surgiram, como o cabrestante e o moinho (WILSON, 2004).

A roda foi uma dessas invenções que melhorava a eficiência nas tarefas. O seu uso promoveu uma grande mudança na forma de transporte e locomoção terrestre. A partir dessa invenção, ocorreu a expansão da exploração e da comercialização de novas terras para transportar suas mercadorias. $\mathrm{O}$ uso da roda popularizou a fabricação de charretes e carroças, veículos que eram movidos por tração animal (RODRIGUE, 2017).

Segundo Wilson (2004), o primeiro veículo a propulsão humana inventado na história foi a carroça, que era movida por pessoas andando a pé no ano de 1690, na França. Em 1817, na Alemanha, que surgiu a primeira bicicleta, que viria a se tornar o veículo de propulsão humana mais popular do mundo.

Por causa dessa popularidade, é comum na narrativa histórica do ciclismo ser resumida apenas a bicicleta que existe hoje, negligenciando formas de bicicletas do passado.

A importância da bicicleta como veículo de propulsão humana é indiscutível. A sua popularidade é reconhecida ao longo da história e se mantém até os dias atuais, abrangendo diferentes países, regiões e gerações.

\section{0 presente da mobilidade urbana}

As invenções dos diversos veículos, sejam de propulsão humana, sejam movidos a combustíveis fósseis, sofreram algumas modificações significativas nas últimas décadas. Houve uma mudança na vida das civilizações, cuja principal mudança foi um grande aumento na quantidade de pessoas vivendo em grandes centros urbanos. Isso ocorreu devido ao grande fluxo migratório, conhecido como êxodo rural, a partir do qual um grande número de pessoas migrou das zonas rurais para as grandes cidades em busca de melhores oportunidades.

Esse fenômeno ocorreu, e ainda ocorre, principalmente nos países em desenvolvimento. Segundo um relatório das Nações Unidas (UN, 2018), esses países possuem uma taxa de crescimento urbano superior ao que os países desenvolvidos tiveram no passado, como pode ser visto na Fig.1, que mostra a taxa de crescimento urbano quando comprado ao crescimento rural. É fácil perceber a tendência crescente da inversão do movimento populacional rural para urbano que vem ocorrendo desde a década de 50 . Observa-se que, em aproximadamente 30 anos, a inversão deverá ter sido alcançada. 
Figura 1-Distribuição da população mundial entre zona rural e urbana.

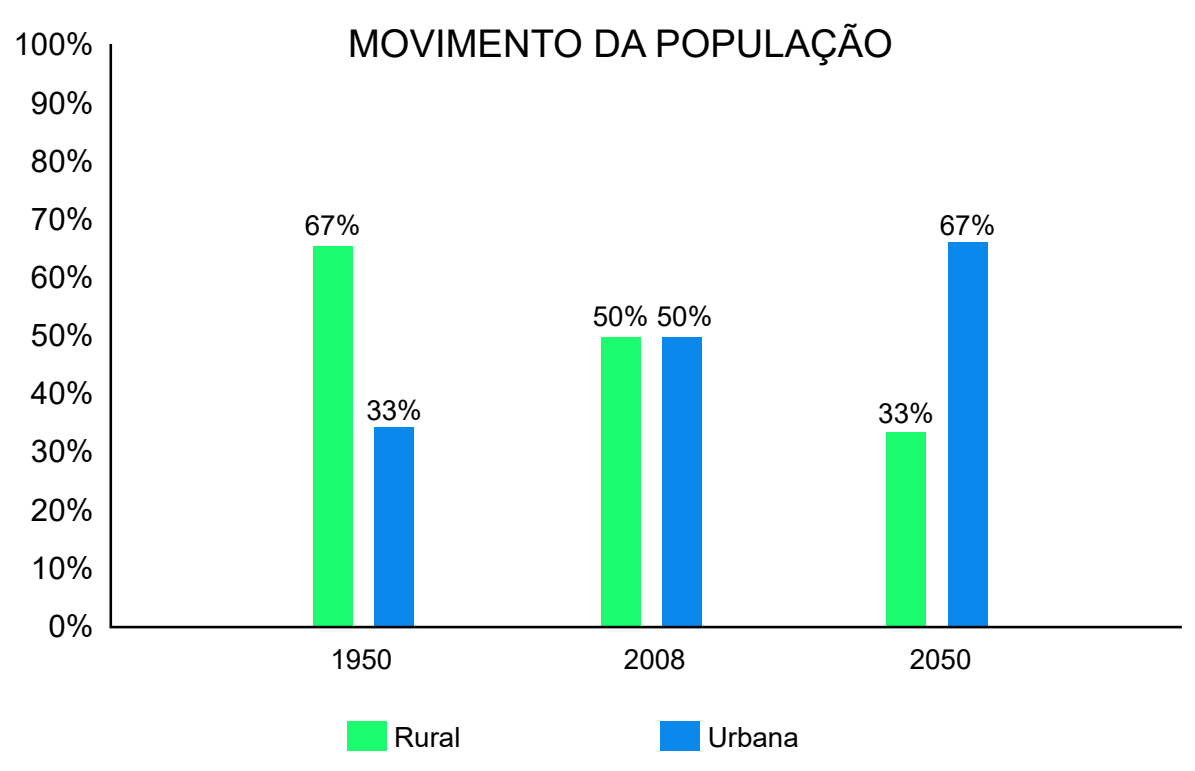

Fonte: Ernest e Young, 2017.

O intenso crescimento fez com que as cidades com maior número de habitantes necessitassem de maior diversificação e oferta de meios de transporte. Um dos efeitos desse rápido crescimento populacional foi o aumento da área das cidades. Associado a isso, o aumento do número de veículos automotivos e das distâncias percorridas diariamente pioraram a mobilidade urbana e prejudicaram a eficiência dos meios de transporte.

Durante muito tempo, este foi o modelo de sistema de transporte público mais comum em grandes centros urbanos, nos quais os modais não motorizados ou a propulsão alternativa, incluindo a humana, não tiveram o mesmo incentivo.

Nesse contexto de crescimento do uso de veículos automotivos, os tamanhos das cidades fizeram com que o trânsito se tornasse um problema. Os grandes centros urbanos possuem congestionamentos crônicos.

Assim, uma das principais ações para diminuir a quantidade de veículos automotivos foi a substituição gradual dos meios de transporte e a melhoria organizacional das cidades, o que permitiu à população optar por outros modais menos problemáticos.

O trânsito gerado pelo uso intensivo de automóveis torna o deslocamento em grandes cidades um desafio nos dias de hoje. Os veículos automotivos ocupam um grande espaço físico nas vias urbanas e, em muitos deslocamentos, o potencial de transporte de pessoas em automóveis de passeio é subutilizado, pois é comum a utilização deste tipo de transporte para locomover uma ou duas pessoas.

A Figura 2 exemplifica esse problema, mostrando que a mesma quantidade de pessoas pode ser transportada por um único ônibus, por dezenas de bicicletas e por dezenas de automóveis. Além disso, é fácil perceber, nas fotografias da Fig. 2, que o volume de ocupação da via é muito menor com o ônibus e com as bicicletas, mas o volume ocupado na via urbana pelos automóveis supera, e muito, os outros meios de transporte. 
Figura 2 - Espaço ocupado para o transporte do mesmo número de pessoas para ônibus, bicicletas e automóveis.
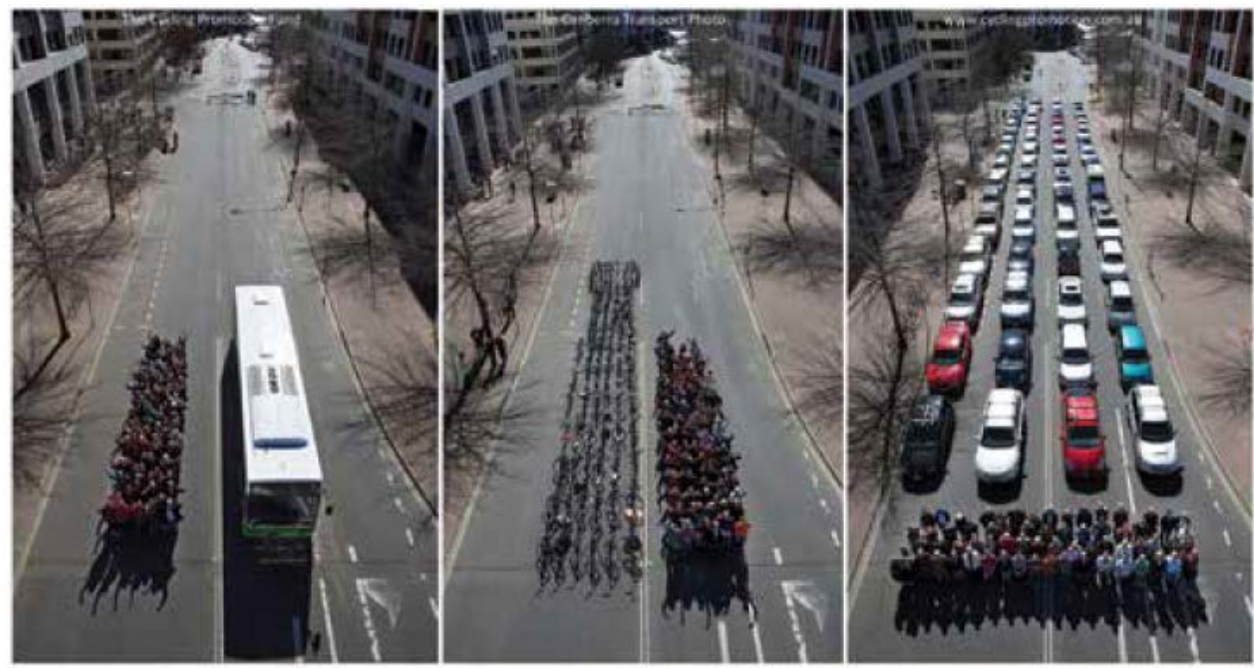

Fonte: Dixon et al. 2019.

Uma das consequências do espaço ocupado pelos veículos é a expansão dos efeitos dos congestionamentos que tornam os centros urbanos, que possuem uma alta densidade populacional, uma região de difícil locomoção e mobilidade.

Além disso, o congestionamento gerado pelo uso extensivo de automóveis é intensificado em determinados horários, como o início da manhã e o final de tarde, tornando o deslocamento das pessoas nas cidades um desafio maior pelas condições de trânsito nesses horários.

Dessa forma, se faz necessário repensar o modelo de crescimento e infraestrutura das cidades, possivelmente desocupando progressivamente os centros comerciais urbanos, porém uma das consequências da desocupação dos centros comerciais das cidades é o progressivo aumento das distâncias percorridas pelas pessoas do trabalho até suas residências, dificultando a utilização de transportes menos rápidos e não motorizados.

Esse fenômeno, da expansão do uso de automóveis em detrimento de outros modais, ocorreu em quase todos os países. No Brasil (MACHI; ALONSO, 2015 ; CET SP, 2018), na cidade de São Paulo, o aumento da frota de automóveis foi incentivado pelas esferas governamentais, não só devido ao crescimento do tamanho das cidades, mas também devido aos subsídios concedidos pelo governo.

O efeito disso pode ser observado na Tabela 1, no qual é possível observar a composição da frota da cidade de São Paulo no ano de 2017.

Segundo uma pesquisa de mobilidade na região metropolitana de São Paulo realizada pelo METROSP (2013), a quantidade de carros particulares, entre 2007 e 2012, na cidade de São Paulo, cresceu 18\%, enquanto o incremento de transporte não motorizado foi de apenas $8 \%$.

Tabela 1 - Composição da frota da cidade de São Paulo em 2017.

\begin{tabular}{lc}
\hline Tipo de transporte & Composição da frota (\%) \\
\hline Automóvel & $79,2 \%$ \\
Motocicleta & $15,3 \%$ \\
Ônibus urbano & $2,7 \%$ \\
Caminhão & $1,5 \%$ \\
Ônibus fretado & $0,4 \%$ \\
Bicicletas & $0,9 \%$ \\
\hline
\end{tabular}

Fonte: CETSP, 2018. 
A taxa de veículos motorizados nesse período foi de 212 (duzentos e doze) veículos para cada 1.000 (mil) habitantes. Também foi identificado um aumento expressivo no uso de automóveis. Essas mudanças fizeram com que o volume de tráfego variasse significativamente. Como consequência, o sistema viário tornou-se incapaz de atender essa demanda crescente.

Em muitas cidades, a solução proposta para contornar esse problema foi a expansão das vias existentes e a construção de novas rotas, através de altos investimentos públicos. Entretanto os efeitos desses investimentos não trazem a redução dos congestionamentos. A expansão da infraestrutura viária, na maioria das cidades, é insuficiente em comparação com a demanda solicitada.

Um estudo realizado pela Escola de Planejamento Urbano de Montreal (MACHI; ALONSO, 2015) mostra que a estratégia de investimentos, ao invés de resolver o problema, na verdade, agravou, pois incentivou o aumento da frota veículos automotivos. Esse efeito negativo é observado, principalmente, em médio e longo prazo. Portanto, pode-se concluir que uma das soluções para os problemas crônicos de trânsito passa pelos incentivos e substituição dos modais de transporte, e não só pelos investimentos na expansão ou melhorias da malha viária.

Nesse contexto, a bicicleta possui um papel importante, pois seu tamanho, sua propulsão e a infraestrutura requerida é muito menor que um automóvel.

Além disso, em muitas cidades, essa infraestrutura pode estar associada a uma mudança positiva nas paisagens urbanas e à implantação de ciclovias em margens de rios, córregos e parques, melhorando a qualidade ambiental e paisagística.

A partir da década de 1970, surgiram as preocupações ambientais e com congestionamentos frequentes nas cidades, além da preocupação com a falta de segurança referente aos ciclistas urbanos, o que fez com que os países começassem a mudar a maneira de tratar o transporte urbano.

A expansão desenfreada e crescente da utilização de automóveis leva a um futuro não sustentável da mobilidade urbana, tanto do ponto de vista socioambiental quanto econômico. O planejamento urbano das cidades deve considerar uma alternativa novos e inteligentes modais.

\section{O Futuro da mobilidade urbana}

Em países da Europa o uso de automóveis tem sido substituído, principalmente, por transportes públicos, como metrôs e trens, e também por veículos de propulsão humana, como a bicicleta. A redução do uso de veículos automotivos é motivada pelos custos na compra, custos de manutenção, custo dos combustíveis e pelo tempo gasto em congestionamentos.

Dessa forma, a bicicleta torna-se uma alternativa relevante para contornar esses problemas, de modo que o investimento em políticas de incentivo a esse modal é uma tendência na nossa sociedade moderna. Algumas cidades, principalmente nos países desenvolvidos, possuem uma cultura de infraestrutura desenvolvida que estimula e cuida dos ciclistas. A bicicleta é, provavelmente, o modal de transporte urbano mais sustentável desenvolvido pela sociedade (PUCHER; BUEHLER, 2017), viável não só para pequenas viagens, como também para percursos médios e longos.

Por conta das características desse modal, que é por natureza ecologicamente correto e importante para condicionamento físico humano, é também importante na redução da necessidade de espaço físico necessário e economicamente viável, tanto relativo ao equipamento quanto na infraestrutura necessária.

Atualmente, a bicicleta tem despertado muita atenção da comunidade científica, principalmente em seus novos desenvolvimentos. Nos últimos anos, observou-se forte tendência de pesquisas relacionadas a esse modal, conforme pode ser visto na Fig.3. 
Figura 3 - Média anual de publicações sobre bicicletas divididas em períodos de cinco anos. Baseados nas revistas especializadas TRID, Web of Science e TRB Comitee for Bicycle.

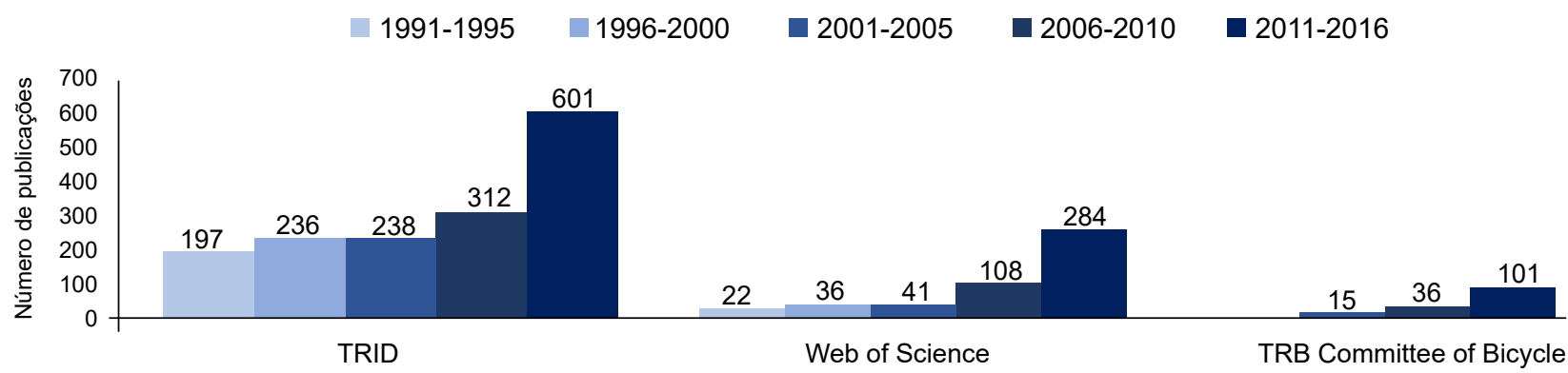

Fonte: Pucher e Buehler, 2017.

Além do aumento das pesquisas sobre bicicletas, é observado, também, um crescimento de conferências acadêmicas a respeito das bicicletas e suas derivações em diferentes países. Cada vez mais é possível observar novas organizações internacionais de divulgação e melhorias nas bicicletas. Com isso, é promovido de maneira consistente esse meio de transporte urbano.

Experiências bem-sucedidas de incentivo ao uso das bicicletas em alguns países, como Holanda, Dinamarca e Alemanha, reforçam a possibilidade desse modal ser utilizado de maneira mais ampla. Na Figura 4 é possível notar os países pioneiros na ampla utilização desse meio de transporte urbano, assim como as diversas cidades no mundo que estão acompanhando essa tendência.

Figura 4 - Porcentagem de percursos realizados utilizando bicicleta.

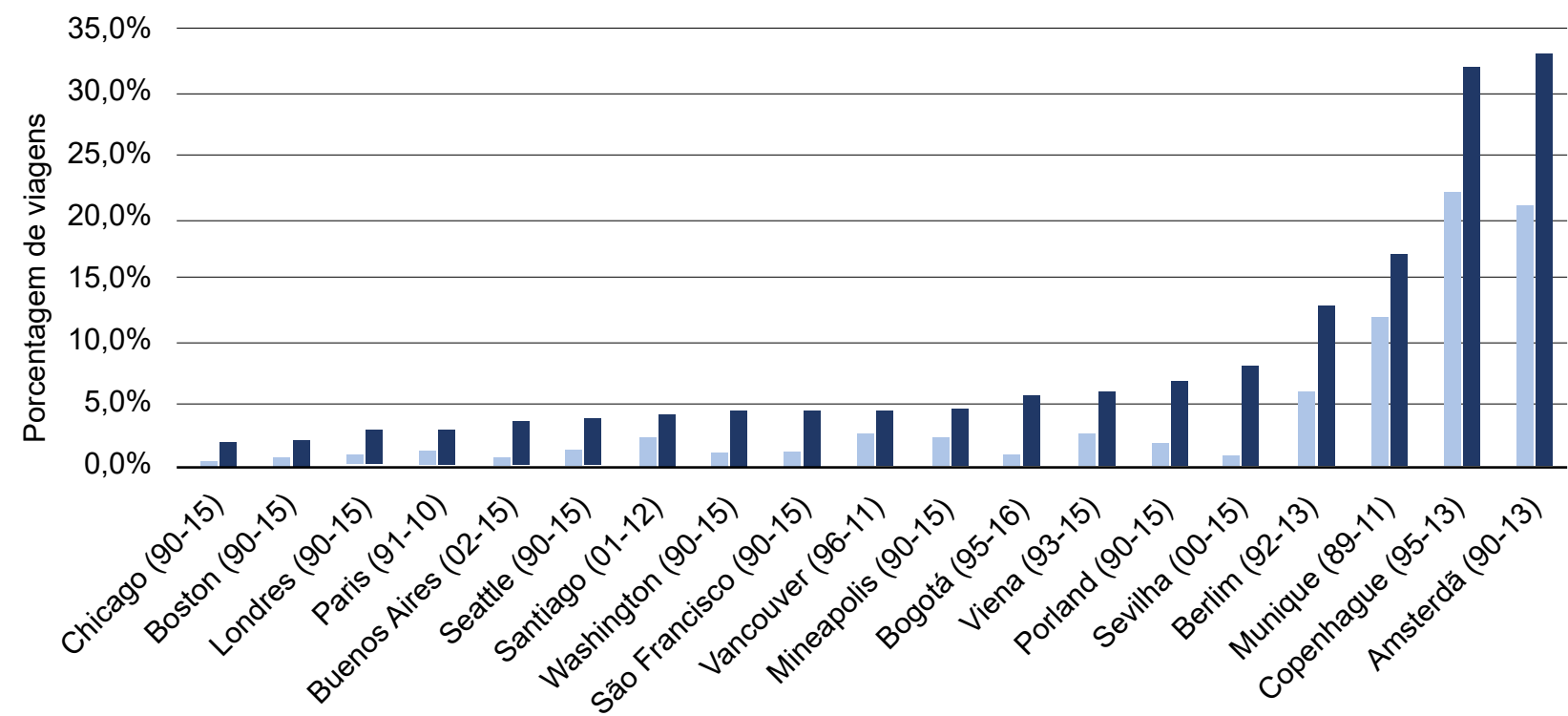

Fonte: Pucher e Buehler, 2017.

O uso de bicicletas deve aumentar nos próximos anos devido às recentes inovações (PUCHER; BUEHLER, 2017), tais como: compartilhamento de bicicletas (bikesharing) e a ampla comercialização de bicicletas elétricas (e-bikes).

O primeiro sistema em larga escala de compartilhamento de bicicletas foi criado na cidade francesa de Lyon, em 2005 (FISHMAN, 2016), com cerca de apenas 1.500 (mil e quinhentas) bicicletas. Hoje, o mundo possui cerca de 1.300 (mil e trezentos) sistemas de compartilhamento de bicicletas com milhares de unidades, 
quase o mesmo número do total de bicicletas que teve início o primeiro sistema de compartilhamento. Hoje, esses sistemas espalhados pelo mundo totalizam cerca de três milhões e meio de bicicletas operando no modo de compartilhamento.

Essa forma de utilização aumentou de maneira significativa a disponibilidade de bicicletas, flexibilizou as rotas de transporte, e possibilitou o uso em conjunto com outros meios de transporte, como os metrôs. Esses sistemas estão amadurecendo tecnologicamente e devem haver um grande aumento nessa forma de utilizar as bicicletas.

Ao mesmo tempo, observa-se que o uso desse tipo de serviço diminui o número de viagens de veículos automotivos entre $2 \%$ e $21 \%$, dependendo da cidade analisada. A cidade de Londres, no Reino Unido, foi a que conseguiu a menor redução (2\%), e em Brisbane, na Austrália, a maior redução (21\%) de uso de automóveis (FISHMAN et al., 2014).

Outra inovação são as bicicletas com tração híbrida (humano-elétrica), as chamadas e-bikes. Cerca de $90 \%$ das bicicletas, mais de quarenta milhões, estão localizadas na China (CAMPBELL et al., 2016), mas o número de e-bikes no norte da Europa tem aumentado rapidamente. Na Holanda e Bélgica, as e-bikes respondem por cerca de 30\% de todas as vendas de bicicletas em 2016.

A e-bike tem a vantagem de auxiliar o condutor em trechos de subida e em grandes distâncias. Sua utilização complementa o uso de bicicletas convencionais, pois as políticas e infraestrutura para uso desses modelos são similares.

Os grandes centros urbanos possuem problemas crônicos relativos ao transporte público, sendo a principal forma de locomoção o uso de veículos automotivos, mas a bicicleta apresenta uma alternativa viável e crescente em todo o mundo.

O aumento no número de pesquisas científicas, grupos e comunidades especializadas, compartilhamento e utilização de e-bikes permite que a bicicleta ocupe uma importante posição na solução da mobilidade urbana no futuro, provavelmente protagonizando sua utilização nas cidades do mundo.

\section{A Discussão do futuro da mobilidade urbana}

O desenvolvimento de novas tecnologias e o crescimento das cidades e da população urbana ao redor do mundo são importantes variáveis no contexto de novas formas de mobilidade.

Um estudo das Nações Unidas (2018) mostra que, atualmente, $54 \%$ da população mundial vive em cidades e que, em 2050 , esse número irá aumentar para $66 \%$ (como pode ser observado na Figura 1). Além disso, segundo Hannon et al. (2016), a densidade populacional irá aumentar em 30\% nos próximos 15 anos. Essa mudança de concentração de pessoas irá representar um grande desafio para o transporte nos próximos anos, principalmente para o modelo de mobilidade centrado no automóvel.

Um dos principais motivos para o aumento dos congestionamentos de trânsito nas grandes cidades é o uso de automóveis, pois a relação entre espaço ocupado nas ruas por quantidade de pessoas transportadas em um carro é muito alta em relação a outros meios de transporte, como bicicleta, ônibus ou metrô. Para contornar esse problema, alguns países estão promovendo o uso racional de veículos, uma vez que o investimento em novas estradas ou rodovias, muitas vezes, não acarretam em melhorias expressivas no trânsito.

Estudos realizados em cidades americanas mostram que há uma relação entre a quantidade de rodovias (fornecimento) e de quilômetros percorridos por veículos (demanda). Investimentos em estradas acabam incentivando maiores percursos por condutores, mantendo o equilíbrio de fornecimento e demanda, ou seja, acabam não melhorando o trânsito de maneira definitiva (DURANTON; TURNER, 2011).

Para contornar o problema de congestionamento provocado por automóveis, algumas cidades estão adotando medidas em curto prazo para limitar o uso de veículos, como aplicação do rodízio, criando de zonas que restringem o uso de automóveis, além da cobrança de pedágios urbanos, acarretando uma diminuição do uso de automóveis no futuro. 
Observa-se também, que alto custo econômico para manter um veículo automotivo particular tem desmotivado a aquisição pelos mais jovens. Esse efeito é notado de maneira mais relevante nas novas gerações, de acordo com uma pesquisa realizada pela Academia Nacional de Ciências dos Estados Unidos (NASEM, 2013). A geração de pessoas chamadas de millennials, que nasceram entre 1980 e 2000, possui cada vez menos interesse na utilização de veículos próprios automotivos.

No Brasil, pode-se observar essa tendência de menor interesse nas novas gerações humanas em possuir um veículo automotivo próprio, a partir dos números de novas habilitações concedidas no país.

Segundo dados do Denatran (2018), o número de novos motoristas habilitados, entre 18 e 21 anos, caiu $20 \%$ de 2014 a 2017. O menor interesse das novas gerações em possuir um automóvel pode ser observado em um aumento na utilização do transporte de pessoas via aplicativos de celular e outros modais.

Segundo Rode e Floater (2014), os aplicativos de transporte via celular é utilizado por cerca de $70 \%$ dos habitantes de Londres. Em Sidney são registradas mais de 40 (quarenta) milhões de solicitações de informação sobre viagens por mês.

A proliferação dos celulares também tem mudado a mobilidade urbana. Hoje é cada vez mais comum a utilização de aplicativos para verificar as condições de trânsito, para solicitar um serviço de táxi, para compartilhar uma bicicleta ou um patinete elétrico.

Nesse contexto de utilização de tecnologia da informação, há grande oportunidade nos serviços de compartilhamento de transporte.

Já existe esse tipo de serviço para bicicletas e patinetes, e a tendência é que se replique para outras formas de transporte. No caso do automóvel, o potencial desse serviço é grande, pois a utilização ainda é baixa, segundo Rode e Floater (2014).

Isso pode ser observado dado que uma pessoa que vai trabalhar durante oito horas por dia deixa o veículo estacionado, e isso equivale a cerca de $96 \%$ do tempo total. Além disso, cerca de $0,8 \%$ do tempo o motorista fica procurando uma vaga, $0,5 \%$ do tempo no trânsito cotidiano e apenas $2,6 \%$ do tempo realmente se locomovendo da residência ao local de trabalho.

O investimento para explorar novas maneiras de se locomover tem aumentado ano após ano e se mostra uma tendência mundial. Segundo um estudo realizado pela consultoria McKinsey (LETZ et al.,2019), foram investidos mais de 220 (duzentos e vinte) bilhões de dólares em startups de mobilidade desde 2010. São mais de 1.100 (mil e cem) empresas de diferentes segmentos de transporte, como veículos elétricos, empresas de tecnologias de compartilhamento, de trânsito inteligente, entre outras. Esses dados são relevantes, pois reforçam a transformação da mobilidade urbana no mundo.

\section{Conclusão}

O menor interesse das novas gerações humanas na utilização de um automóvel particular como forma de transporte principal está associado a diversos fatores, como o aumento da densidade da população urbana, o uso de aplicativos de transporte e os investimentos em novas formas de mobilidade, mostrando que o modelo de mobilidade urbana centrado no automóvel deverá diminuir significativamente no futuro. Esse fenômeno é observado no mundo todo, mas de maneira mais clara em países desenvolvidos, os quais já utilizam outras formas de transporte.

Nos grandes centros urbanos mundiais, é cada vez mais popular a utilização de outras formas de transporte urbano, e várias são complementares. Pequenos trajetos urbanos até estações de metrô, barcos ou trens podem ser realizados por bicicletas ou pequenos veículos elétricos (triciclos ou patinetes), que podem ser utilizados de maneira compartilhada através de aplicativos de celulares.

O uso de veículos com propulsão humana possui grande vantagem sobre outros meios de transporte, tanto no custo de deslocamento quanto no custo de poluição urbana. Além, é claro, da constante ajuda na 
saúde humana pela prática de exercícios físicos rotineiros. Assim, possui importante significado para as novas gerações.

Por fim, esse fenômeno, associado à mudança na forma de se locomover nas cidades, vem sendo acompanhado com grande interesse pela comunidade científica, assim como também por investidores no desenvolvimento de produtos inovadores.

Esses indicadores mostram uma clara tendência de mudança na mobilidade urbana, reforçando a necessidade de que os governos, as empresas, os usuários e os acadêmicos atentem para esse fenômeno, buscando oportunidades para criar equipamentos e dispositivos mais eficientes e ecologicamente corretos para o transporte humano.

\section{Agradecimentos}

Os autores agradecem a Universidade de Taubaté - Unitau por fazerem parte do Programa de Mestrado em Engenharia Mecânica, como estudante e professor. O segundo autor aproveita a oportunidade para agradecer o apoio financeiro concedido pela empresa de pesquisa, tecnologia e serviços da universidade de taubaté - EPTS, o qual permitiu o desenvolvimento desta pesquisa.

\section{Referências}

CAMPBELL, A. A. et al. Factors influencing the choice of shared bicycles and shared electric bikes in Beijing. Transportation Research Part C: Emerging Technologies, [S. I.], v. 67, p. 399-414, 2016. COMPANHIA DE ENGENHARIA DE TRÁFEGO DE SÃO PAULO. Pesquisa de monitoração da mobilidade, volume e velocidade. São Paulo: CETSP, 2018.

DEPARTAMENTO NACIONAL DE TRÂNSITO. Dados referentes à novas habilitações concedidas. Brasília: DENATRAN, 2018.

DIXON, S. et al. Gauging global readiness for the future of mobility. New York: Deloitte City Mobility Index, 2019.

DURANTON, G.; TURNER, M. A. The fundamental law of road congestion: evidence from US Cities. American Economic Review, Pennsylvania, v. 101, n. 6, p. 2616-2652, 2011.

ERNEST e YOUNG. Is your city as smart as its residents? Quartz Creative Services. United States: Ernst \& Young Global, 2017.

FISHMAN, E. Bikeshare: a review of recent literature. Transport Reviews, [S. I.], v. 36, n. 1, p. 92-113, 2016.

FISHMAN, E.; WASHINGTON, S.; HAWORTH, N., Bike share's impact on car use: evidence from the United States, Great Britain, and Australia. Transportation Research Part D, Transport and Environment, [S. I.], v. 31, p. 13-20, 2014.

HANNON, E. et al. An integrated perspective on the future of mobility. McKinsey \& Company Sustainability \& Resource Productivity, Amsterdã, p. 1-5, 2016.

INTERNATIONAL ENERGY AGENCY. World energy balances: overview international. Paris: IEA, 2018.

LETZ, D. H. et al. Start me up: where mobility investments are going. Sustainability \& Resource Productivity, Amsterdã, [S. I.], p. 1-8, 2019.

MACHI, C.; ALONSO, M. A. Bicicleta como modal de transporte sustentável para a cidade de São Paulo: o estudo de caso da Trilha Norte-Sul. Rev. Labverden, São Paulo, Brasil, v. 10, p. 34-60, 2015. 
METRO DE SÃO PAULO. Pesquisa de mobilidade da Região Metropolitana de São Paulo. São Paulo: Diretoria de Planejamento e Expansão dos Transportes Metropolitanos, 2013.

NATIONAL ACADEMIES OF SCIENCES, ENGINEERING, AND MEDICINE. Millennials and mobility: understanding the millennial mindset and new opportunities for transit providers. Washington: National Academies of Sciences, Engineering, and Medicine, 2013.

PUCHER, J.; BUEHLER, R. Cycling towards a more sustainable transport future. Transport Reviews, [S. I.], v. 37, n. 6, p. 689-694, 2017.

RODRIGUE, J. P.; COMTOIS, C.; SLACK, B. The geography of transport systems. 4. ed. New York: Routledge, 2017.

RODE, P.; FLOATER, G. Accessibility in cities: transport and urban form. NCE Cities, London, v.3, p. 1-61, 2014.

SILVEIRA, M.; MAIA, M., Variáveis que influenciam no uso da bicicleta e as crenças da teoria do comportamento planejado. Transportes, São Paulo, v. 23, n. 1, p. 24-36, 2015.

UNITED NATIONS. The speed of urbanization around the world. United Nations, 2018.

WILSON, D. G. Bicycling science. 3. ed. Cambridge: Massachusetts Institute of Technology, 2004.

\section{Sobre os autores}

\section{Gabriel Campbell de Oliveira}

Mestrando em Engenharia Mecânica pela Universidade de Taubaté (UNITAU) na área de Energia e Materiais e graduado em Engenharia Mecânica pela Universidade Federal do Rio de Janeiro (UFRJ). Tem experiência na área de Engenharia Mecânica, com ênfase em projetos de máquinas, tanto acadêmicas quanto profissionais.

\section{Filipe Wiltgen (L.F.W. Barbosa)}

Doutor em Dispositivos Eletrônicos e Computação na área de Fusão Termonuclear Controlada utilizando inteligência artificial para controle do plasma de Tokamaks pelo Instituto de Tecnologia de Aeronáutica (ITA) em 2003. Mestre em Dispositivos Eletrônicos e Computação na área de Fusão Termonuclear Controlada utilizando controle de campos magnéticos para confinamento e produção de plasma em Tokamaks pelo Instituto de Tecnologia de Aeronáutica (ITA) em 1998. Graduado em Engenharia Elétrica com ênfase em Eletrônica de Potência pela Universidade de Taubaté (UNITAU) em 1994. Atualmente atua como professor no Programa de Mestrado em Engenharia Mecânica e como coordenador e professor do curso de pós-graduação Especialização em Energia Solar Fotovoltaica na Universidade de Taubaté (UNITAU).

Recebido em: 30/09/2019

Aceito em: 15/12/2019 